\title{
Processes Responsible for Cloud Feedback
}

\author{
A. Gettelman' ${ }^{1}$ (D) S. C. Sherwood ${ }^{2}$
}

Published online: 1 October 2016

C) Springer International Publishing AG 2016

\begin{abstract}
Cloud feedback on global climate is determined by the combined action of multiple processes that have different relevance in different cloud regimes. This review lays out the framework for cloud feedback and highlights recent advances and outstanding issues. A consensus is emerging on large-scale controls on cloud feedback. Recent work has made significant progress in the understanding and observationally constraining the local response of shallow clouds. But significant uncertainties remain in microphysical mechanisms for cloud feedback. Important microphysical mechanisms include cloud phase changes, precipitation processes and even aerosol distributions. The treatment of these processes varies across climate models and may contribute to greater spread in feedbacks across models as models advance. Future work will need to try to bound the range of possible cloud microphysical feedback mechanisms and seek observational constraints on them.
\end{abstract}

Keywords Cloud . Climate feedback · Climate change . Climate sensitivity

This article is part of the Topical Collection on Climate Feedbacks

A. Gettelman

andrew@ucar.edu

S. C. Sherwood

s.sherwood@unsw.edu.au

1 National Center for Atmospheric Research, 3090 Center Green Drive, Boulder, CO 80301, USA

2 Climate Change Research Centre, and Australian Research Council Centre of Excellence for Climate System Science, University of New South Wales, Sydney, New South Wales, Australia

\section{Introduction}

Clouds are a critical part of the global climate system. They exert a strong radiative cooling on the planet $\left(\sim-20 \mathrm{Wm}^{-2}\right)$ as the residual of a larger cooling effect $\left(\sim-50 \mathrm{Wm}^{-2}\right)$ and a positive warming effect $\left(\sim 30 \mathrm{Wm}^{-2}\right)$ [54] depending on cloud type and optical thickness. Any changes to cloud radiative effects in response to radiatively forced changes in climate are not an external forcing, but an internal cloud feedback that amplifies or damps the forcing. Because of the number of different cloud types and regimes, and the dependence of clouds on both micro- and macro-physical influences, cloud feedback on climate represents the largest uncertainty in our ability to understand the sensitivity of the planet to radiative forcing $[16,20,51]$.

There has been significant work in the last few years in new methodologies $[65,66]$ and new understanding (reviews by [19, 33]) of cloud feedback. It is now clear that there are different mechanisms and processes responsible for cloud responses to radiative forcing in different regimes. But many uncertainties remain, and many relate to how specific cloud processes and regimes affect cloud feedback.

This review seeks to synthesize recent work about the processes that are responsible for cloud feedback. We review the basic cloud feedback paradigm and cloud regimes in "Cloud Feedback Paradigm". We then discuss the processes affecting cloud feedback in different regions ("Cloud Feedback Processes") and aerosol-mediated cloud feedback in "Aerosol-Mediated Cloud Feedback". We discuss observational evidence and constraints on how cloud processes may change in "Observations of Cloud Feedback and Emergent Constraints". Summary and conclusions are in "Discussion". 


\section{Cloud Feedback Paradigm}

\section{Physics of Cloud Radiative Effects}

Clouds influence the global radiation budget by reflecting sunlight (a cooling influence) and by adding to the greenhouse effect (a warming influence). The cloud radiative effect (CRE) thus has shortwave (SW) and longwave (LW) components.

The shortwave CRE of a cloud is proportional to the cloud albedo relative to clear sky. The former is determined mainly by optical thickness $(\tau)$, which for liquid clouds is approximately

$\tau \sim L^{5 / 6} N_{c}^{1 / 3}$

where $L$ is the liquid water path (LWP) and $N_{c}$ the cloud drop number concentration [70, Eq. 19]. Optical thickness ranges from small values $(\tau \ll 1)$ for thin or sub-visible $(\tau<0.01)$ ice clouds, which reflect very little sunlight, up to several hundred for opaque and deep clouds whose albedo can approach $70 \%$ or more. Increases in $N_{c}$ can increase cloud albedo if $L$ is unaffected. However, cloud SW feedback is likely to be dominated by changes in $L$ or cloud cover or phase. For ice, $\tau$ is affected strongly by the optical properties of the shape of ice crystals, which are highly variable.

The greenhouse effect (LW CRE) of an opaque cloud $(\tau \gg 1)$ is determined by the difference between the temperature of the cloud top and the clear sky effective emitting temperature. This difference increases with the altitude of the cloud top. Clouds with water contents below about 20 $\mathrm{gm}^{-2}$ [53], which includes many cirrus clouds, will usually not be opaque. In this case, their LW CRE is diminished, vanishing to zero as $\tau$ approaches zero. While LW CRE saturates once $\tau$ much exceeds unity, SW CRE continues to increase even to very high $\tau$. This is because SW photons are scattered while LW ones are mostly absorbed: many SW photons can penetrate a cloud even if its $\tau$ is very high, but the likelihood of this decreases the higher $\tau$ becomes.

For most clouds in the present climate, SW CRE dominates over LW CRE. Exceptions are high thin or sub-visible cirrus clouds, whose low $\tau$ produces negligible albedo but a non-negligible greenhouse effect. Net cloud feedback on climate arises because of a shift in the balance of LW and SW influences. Such a shift can come either from changes in the location or extent of clouds, or from changes to their optical properties.

\section{Feedback Framework}

Roughly speaking, cloud feedback $(C F)$ is a response of $\mathrm{CRE}$ to global temperature changes (i.e., $C F=$ $d \mathrm{CRE} / d T_{S}$ ), usually divided into $\mathrm{SW}$ and $\mathrm{LW}$ components. The changes in CRE can be estimated locally. However, because CRE depends on the clear sky emissivity (affected by water vapor, temperature and surface albedo), isolating the cloud feedback requires $d \mathrm{CRE}$ to be corrected for noncloud changes, for example using radiative kernels [51]. Changes in CRE can be decomposed by cloud type: usually by altitude and optical thickness, where the cloud radiative effects and their change are a sum of effects from different cloud types [66]. The decomposition can be done with offline radiative transfer calculations for each cloud type [66] or using observations of clouds and their radiative effects [65]. This decomposition naturally provides the ability to distinguish different cloud regimes that contribute to cloud feedback. Clouds can be examined regionally by height and thickness, although it requires careful interpretation since, for example, a change in the ratio of high to low cloud cover can appear as a height feedback [68].

To determine cloud feedback, cloud changes are predicted as a function of some future global temperature increase $d T_{s}$. We cannot observe a $d T_{s}$ caused by future greenhouse gases, but we can observe naturally occurring perturbations about the current $T_{s}$. If the response is the same to both, then observations can be used as "analogs" of future change (see "Observations of Cloud Feedback and Emergent Constraints"). The problem with such analogs is that observed $d T_{S}$ over the period of good cloud and radiation measurements (the last 10-20 years) mostly result from modes of climate variability (e.g. El Niño Southern Oscillation, ENSO), that have very heterogeneous local temperature signatures and may therefore produce a different cloud response than would a forced climate change [18]. While one could try to overcome this by working out local temperature-cloud relationships, processes responsible for cloud feedback may not be directly related to global or local surface temperature. For example, cloud feedback in low cloud regimes likely depends on ambient humidity in the boundary layer and free troposphere, strength of the PBL inversion and large scale overturning that maintains these processes ("Cloud Feedback Processes"). These processes will not in general be directly related to local $T_{s}$.

So another approach to the problem of cloud feedback has been to determine which cloud processes are responsible for cloud feedback in models and then which models best represent these processes in the present day. The processes are commonly approached from a top down correlation level where a particular property of the cloud climatology or their environment "emerges" as highly correlated with cloud feedback or climate sensitivity (e.g. [48]). Then, the observations of this property provide a "constraint" on cloud feedback (e.g. [19]). 

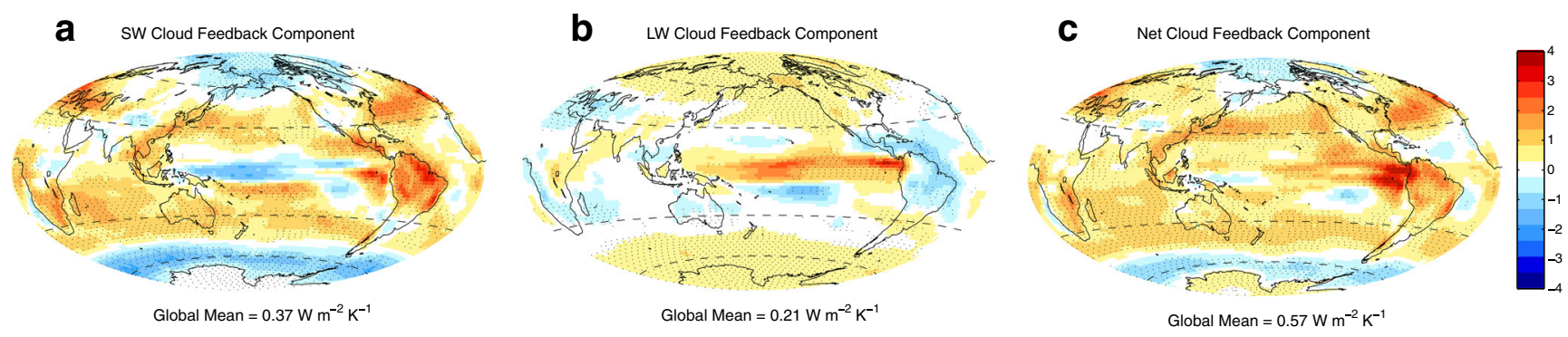

Fig. 1 Map of mean cloud feedbacks for a SW, b LW and $\mathbf{c}$ Net using cloud radiative kernels estimated by 11 models. Reprinted with permission from Zelinka et al. [66]

\section{Spatial Distribution of Cloud Feedback}

In the late 20th century, cloud responses emerged as the main source of disagreement in climate models [13]. Subsequently it became clear that this disagreement largely arose from low-level cloud behavior (e.g. [4]). For low clouds, most changes to CRE will occur through SW radiation especially over the dark oceans. Thus, changes to the cloud optical thickness and extent are prominent. For high cloud amount (and to a lesser extent for high cloud optical thickness changes), impacts will occur in both the LW and SW, largely cancelling in the net radiation. For high cloud altitude changes, only the the LW changes (with cloud top temperature).

Figure 1, adapted from Zelinka et al. [66], shows the spatial distribution of cloud feedback simulated by a set of climate models. The feedback is positive in most regions, with a component from the SW (Fig. 1a) and LW (Fig. 1b) yielding a global mean net feedback of $\sim 0.6 \mathrm{Wm}^{-2} \mathrm{~K}^{-1}$. Shifts in the distribution of high tropical clouds produce contrasting patterns of SW and LW feedback in the tropics but generally with a positive net feedback. Net positive feedback outside of the deep tropics is dominated by positive SW contributions in the sub-tropics and storm tracks in stratus and stratocumulus regimes, implying a reduction in cloud amount or optical depth. The main exception to the overall positive pattern is over the polar oceans, where a strong negative $\mathrm{SW}$ feedback is only partly offset by LW feedback. This comes from clouds with a net cooling effect on the poleward edges of the storm track.

Figure 1 masks significant variations among models. It is particularly useful to examine the across-model relationship between the spatial distribution of cloud feedback and the change in global mean temperature. Figure 2 indicates which regions have cloud feedbacks that are important in driving the spread in climate sensitivity. The regression slopes are weak or negative at high latitudes and over continents, but are positive and large over nearly all other oceans. This confirms that sub-tropical oceans are an important contributor (mainly because of their large area). The responses along the equatorial Pacific and Indian oceans are also important. This picture may vary depending on the ensemble of models considered; for example, Soden and Vecchi [50] found in the earlier CMIP3 model set a slightly
Fig. 2 Regression slope between local net Cloud Feedbacks $\left(\mathrm{Wm}^{-2} \mathrm{~K}^{-1}\right)$ and global temperature change $(\mathrm{K})$ predicted by 2100 under the RCP8.5 scenario among 11 CMIP5 models. Reprinted with permission from Vial et al. [63]
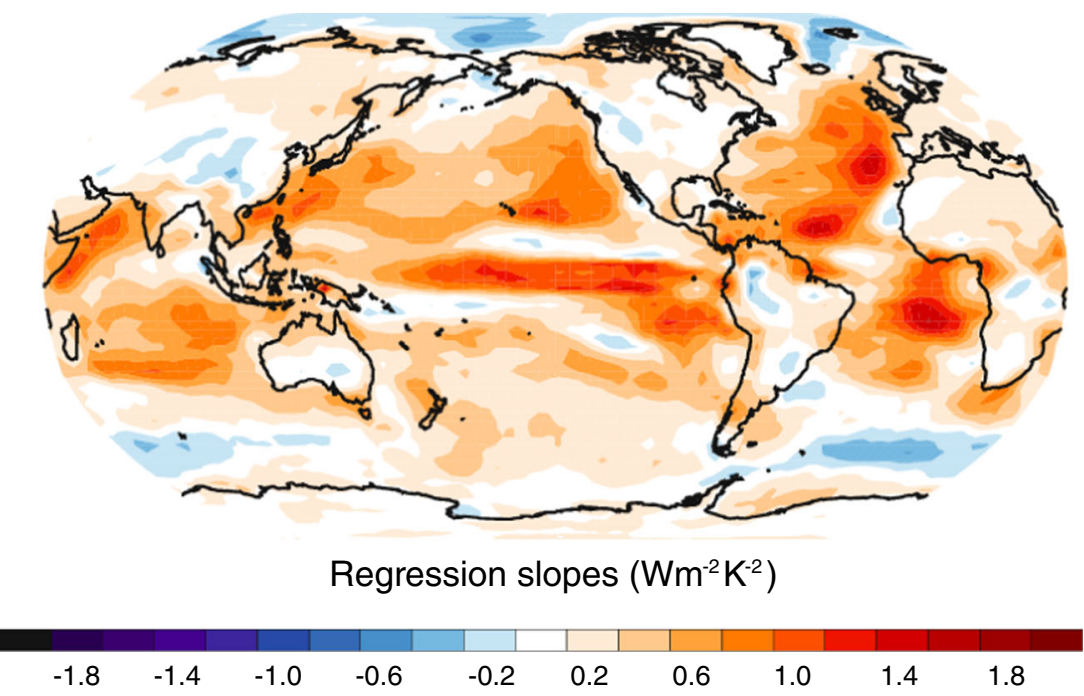
stronger role for marine stratus regions, while Gettelman and Chen [22] found a dominant role for the sub-tropics and mid-latitude storm tracks in explaining changes in climate sensitivity of successive versions of the NCAR model.

\section{Cloud Feedback Processes}

Regional analysis provides a basis for linking cloud types in different locations with specific processes. Recent analyses of climate models and studies employing detailed cloudsystem simulations are rapidly advancing our understanding of the mechanisms likely to cause cloud feedback. Observations are also being used to narrow down which mechanisms are more realistic and how strong they are.

\section{Mechanisms Mediated by the Large-Scale Circulation}

Clouds are strongly coupled to environmental flows and to humidity on large scales $(>100 \mathrm{~km})$ well resolved by current climate models. This leads to expected large-scale shifts in the cloud distribution due to anticipated changes to the circulation and humidity. These processes were emphasized in the most recent IPCC report $[6,20]$ and will be summarized here along with recent work.

\section{High Cloud}

The most important such mechanism is the cloud-height or Fixed-Anvil Temperature (FAT) mechanism. Hartmann and Larson [28] noted that the overturning circulation of the troposphere (convective outflow) balances convective heating and radiative cooling. Since the cooling is mostly due to water vapor, it stops when the temperature becomes too cold to contain an optically thick quantity of water vapor. In this way, the convective outflow level (and hence anvil and thick cirrus clouds) should remain near $200 \mathrm{~K}$ as the temperature warms (though warming slightly due to changes in the air divergence profile, [67]). Thus, the greenhouse effect of high clouds gets larger, because the cloud temperature does not change while the clear sky emission off a warmer surface is larger. There is recent evidence that high cloud tops are getting higher [40]. The magnitude of this feedback is proportional to the area of deep cloud [64].

High cloud area may also expand or contract in response to the large scale overturning circulation and the supply of moisture. It is expected that the overall overturning circulation will slow, reducing the transport of mass into the upper troposphere, which might reduce high cloud fraction although the net feedback effect of this is unclear. It may depend on enhanced convective organization and upper tropospheric stability [5] or precipitation efficiency of deep convective cloud systems that supply moisture to the upper troposphere [35, 71]. A reduction in high clouds is seen in GCMs over land where deep convective uplift slows and the moisture supply is limited and relative humidity drops as land warms faster than oceans [30]. This contributes slightly to positive feedback in models.

\section{Poleward Shift}

The subtropical dry zone and mid-latitude storm tracks appear to be shifting poleward in both observations [2, 40] and simulations [26]. Such shifts are projected as a response to changing equator to pole temperature gradients and baroclinicty [14] resulting from greenhouse gas increases and ozone depletion in the Southern Hemisphere [17]. However, the magnitude of the observed shift depends on the metrics used [17]. Poleward jet shifts would be expected to shift clouds to regions of weaker insolation, giving a positive feedback effect. Grise et al. [27] for example concluded that the ozone-induced poleward jet shift in the southern hemisphere in a single model (CAM3) caused a $0.25 \mathrm{Wm}^{-2}$ net warming due to reduced cloud amount in mid-latitudes. This is not necessarily the case in all models [26].

This picture is complex for several reasons. The area of the storm track regimes may change as it moves poleward. This may alter the balance of cloud radiative effects. Second, changes to cyclone structure or wind speed may be driven by large-scale dynamics (baroclinicity of the equator to pole temperature gradient). Finally, recent studies $[11,31]$ have found that simulated cloud radiative effect changes in storm track regions appear to be dominated by a direct effect of temperature change rather than latitudinal shift of the background cloud field (see "Cloud Phase"). Observations analyzed by Tselioudis et al. [59] confirm this but suggest that tropical expansion does significantly affect cloud cover.

\section{Marine Stratocumulus}

The largest cloud feedback regime is over the subtropical oceans from 20 to $40^{\circ} \mathrm{N}$ and $\mathrm{S}$ latitudes. These regions typically feature low-level trade cumulus, stratocumulus and marine stratus clouds. The stratus-covered regions on the eastern edge of ocean basins in the sub-tropics have large cloud radiative effect (although small area) and contribute significantly to feedback spread among models. These overcast stratus regions have therefore become a particular focus of cloud feedback studies, which for simplicity often focus on the relatively horizontally homogeneous situation of a cloud-topped shallow convecting layer.

Such cloud layers are highly sensitive to the moisture and thermodynamic structure of the planetary boundary layer (PBL) and in particular to the strength of the inversion at 
cloud top. Shallow cumulus clouds are also sensitive to moisture above the PBL (e.g. [45]).

Cloud feedback in the strato-cumulus cloud region is tightly coupled to both the optical depth and the extent of clouds. These factors combine microphysics (see below) with changes to the cloud environment. Recent advances in our understanding of low cloud feedback have recently been reviewed by Kamae et al. [30] and Bretherton [7].

Bretherton [7] reviewed four mechanisms involved in low cloud feedback in high resolution modeling, illustrated in Fig. 3. (1) Inversion strength: observations and theory indicate that the strength of the cloud-topping inversion controls low-cloud cover and/or thickness by suppressing turbulent motions that would break up the cloud and trapping evaporated moisture in the PBL. In a warmer climate, the inversion is expected to strengthen due to the moist-adiabatic profile of temperature increase, promoting more/thicker low cloud, though there are some additional complex interactions [42]. However, stronger inversion and a warmer climate also mean a larger (2) moisture gradient between the boundary layer and troposphere. This means the same amount of turbulent entrainment of air from above the inversion into the cloud layer will have a greater net drying effect, leading to a thinner cloud (see also e.g. [10]), in opposition to \#1. This is similar to the entrainment liquid flux feedback mechanism introduced by Bretherton and Blossey [8] that thins boundary layer cloud. As net low cloud (3) radiative cooling decreases in a warmer world because the atmosphere has more water vapor, it is less efficient at radiating to space. This may decrease turbulent motions at cloud top. On average, turbulence entrains air from above the cloud layer at a rate that matches large-scale subsidence. Thus, to be in balance with a lower subsidence rate, the cloud top will be lower, and it will be thinner [7]. But as subsidence and large-scale ascent driven by (4) dynamics slow in a warmer world, reduced subsidence should thicken and raise the cloud layer, opposing \#3.

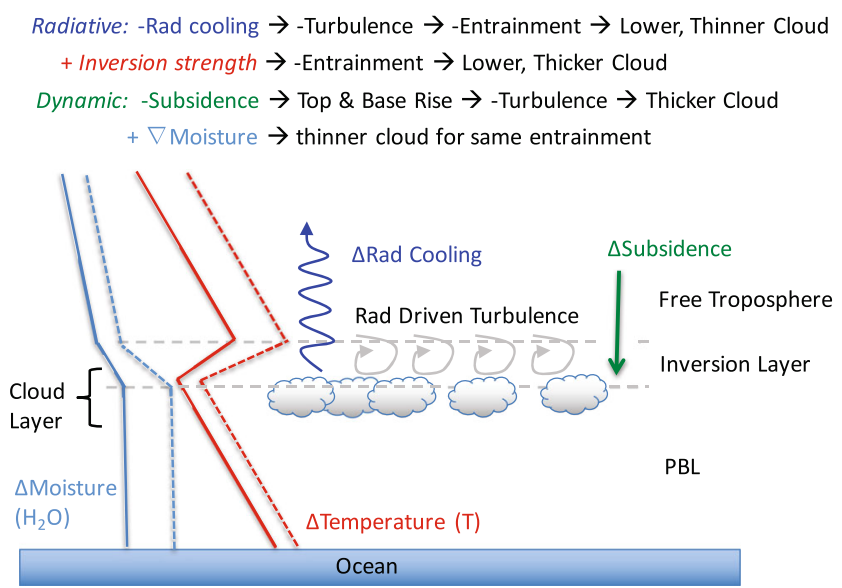

Fig. 3 Marine boundary-layer stratocumulus cloud feedback mechanisms as described in the text following Bretherton [7]
All four of the mechanisms are ultimately linked to increases in water vapor in a warmer climate. The four mechanisms also overlap to some extent since, for example, stronger subsidence also strengthens the inversion and may alter the moisture gradients. While LES studies indicate that the cloud-depleting mechanisms dominate, since cloud feedback is almost always positive [7], it does not provide robust quantitative limits on shallow cloud feedback. Progress toward constraining the net result may therefore require reformulating the problem.

A number of recent studies [38, 41, 42] have attempted to do this by approximating low-cloud amount as a linear function of factors including local SST and a measure of inversion strength. Coefficients in this function are determined empirically, and model feedbacks explored using the same equation. These studies also consider much broader subtropical regimes, rather than only the relatively small area of persistent marine stratus. They find that higher SST (other things equal) reduces cloud amount, that a stronger inversion (other things equal) increases it [38], and that the SST effect accounts for most of the model feedback spread [42]. Observations support an SST effect toward the high end of the model range, thus a strong positive shallow cloud feedback [43].

\section{Convection and the Low-Cloud Problem}

Low cloud feedback can arise in a sub-tropical region extending from just outside the deep convective regions through the equatorward branch of the storm track. This area intercepts roughly half of incoming sunlight and is the largest contributor to positive SW cloud feedback [4, 23]. Much of the area is characterized by isolated shallowto mid-top cumulus clouds that occasionally rain. It is not clear how well the mechanisms $1-4$ above that dominate in a non-raining sub-tropical stratus situation will generalize to this broader sub-tropical region, or generalize to the whole tropics or the mid-latitudes. Similar to the flux mechanism for low cloud described by Bretherton and Blossey [8], Rieck et al. [44] found that increased latent heat flux in a warmer climate drives larger liquid water and buoyancy fluxes in cumulus layers, causing deepening by penetrative entrainment, lowering of relative humidity in the cumulus and subcloud layers, and a consequent slight reduction in cumulus cloud cover and liquid water path. However, given the importance of precipitation formation in the evolution of these clouds and the variations in cloud depth, one must consider whether turbulent-mixing and/or microphysically mediated feedback effects are important.

Indeed, a number of climate model studies have highlighted the important role of shallow and/or deep cumulus convection in simulated global cloud feedback. Gettelman 
et al. [23] noted that the change of shallow cumulus parameterization in the Community Atmosphere Model version 5 (CAM5) significantly increased the climate sensitivity by cloud feedback in the sub-tropics on the equatorward flank of the sub-tropical jet. Subsequent results in another model indicate this is a sensitivity to the entrainment and precipitation efficiency in moderate ascent and subsidence regions [71]. Similarly, Tomassini et al. [57] reported that the climate sensitivity of the MPI-ESM GCM could be changed from 3 to $10^{\circ} \mathrm{C}$ by such convective-scheme changes, although it seems very difficult to produce low sensitivities in the model [35].

However, Webb et al. [64] found that the spread in global cloud feedback among a subset of CMIP5 climate models run for CFMIP with their deep and shallow convective representations switched off did not narrow substantially compared to what it had been in the standard versions of the models. This presents a conundrum since it seems to directly conflict with the aforementioned experiences of teams at individual modeling centers, and deserves further attention. Two factors argue against a dominant role for deep convection in setting overall low-cloud responses. First, local cloud-environment correlations in the presentday climate seem able to predict climate-change responses, at least among "good" models [38]. Second, most of the spread in model responses is attributable to sensitivity to local SST rather than inversion strength [43, Fig. 1], with only inversion strength sensitive to remote convection. But the cloud-environment correlations do not rule out a significant role for shallow convective motions which may also correlate with the environment and may help mediate the SST sensitivity.

Sherwood et al. [48] noted that both small- and largescale circulations will govern mixing of moisture upward out of the boundary layer globally; provided evidence that this transport increases with warming due to the increasing vertical moisture contrast, analogous to mechanism \#2 above for marine stratus; and found that this effect depends on present-day circulations. Observations indicated the relevant circulations are relatively strong, implying cloud feedback toward the high end of the model range, supporting the empirical low-cloud studies noted above. In simulations, Webb et al. [64] found more positive cloud feedback consistent with less moist static energy (MSE) near the top of the PBL $(850 \mathrm{hPa})$ implying stronger mixing and drying of the PBL.

By adjusting convective parameters, Zhao et al. [71] were able to produce versions of the GFDL model with a range of ECS values despite having similar amounts of the mixing implicated by Sherwood et al. [48]. Zhao et al. [71] found that differences in the treatment of autoconversion of cloud water to precipitation resulted in changes to ECS. Cloud feedback was positive or negative depending on how precipitation efficiency was affected by initial water vapor content. If efficiency did not increase, more vapor in updrafts led to approximately adiabatic increases in water provided to mid-level clouds, producing a negative feedback similar to that originally suggested by Somerville and Remer [52]. Studies have suggested that this behavior is unrealistic [61], but this deserves revisiting. Mauritsen and Stevens [35] explore a similar mechanism, noting that highly temperature-dependent precipitation efficiency can produce opposite effects on cloud and water-vapor feedbacks and also strongly affect hydrologic sensitivity.

In summary, climate model behaviour suggests that overall cloud feedback including the important low-cloud contribution is sensitive to precipitation and convective processes on multiple scales. However, it also appears that a significant part of model spread is caused by differences in how low clouds are parameterized [41]. It is likely that low-cloud amount itself can radiatively amplify cloud feedback [9] and drive convective circulations [39], so that multiple low-cloud feedback mechanisms could be linked together and depend on deeper circulations. Microphysical processes for precipitation formation and efficiency may also be important in convective clouds.

\section{Cloud Phase}

Clouds can contain liquid and ice particles of a wide range of sizes and (for ice) shapes. Once large precipitation particles form, they can deplete a cloud of water and limit the size eventually attained by the cloud. Most precipitation in the present climate originates with frozen particles, making the ice phase important for limiting cloud extent. Because of the lower equilibrium vapor pressure over ice compared to liquid [37], ice particles grow rapidly at the expense of liquid when both phases co-occur, reducing cloud optical depth and quickly initiating precipitation which further depletes cloud water content, optical depth and horizontal extent.

At high latitudes, there is a distinctive negative SW cloud feedback (Fig. 1a). This results from a thermodynamic response of cold clouds having more liquid at warmer temperatures, suppressing precipitation and producing higher cloud optical depth and persistence in warmer states [12, $15,22,60]$. The simulated response does not appear to be related to shifts in the storm track ("Poleward Shift"), but rather follows the thermodynamic response to temperature $[11,31]$ and is purely a cloud microphysical phenomenon. This "optical depth" feedback is seen in satellite observations [58] and models [25], though it may be too strong in models [56].

Models have a diversity of approaches for cloud microphysics in the mixed phase, and hence a spread of cloud feedbacks in this region [36]. Complicating matters, 
models tend to have a deficiency in cloud liquid in mid and high latitudes, driving a surplus of absorbed solar insolation and low base state CRE (Flato et al. 2013). This is largely due to missing supercooled liquid water in these regions $[3,55]$ and may contribute to an overestimated negative feedback in these regions by shifting the typical latitude of liquid-ice transitions and, therefore, the latitude where the phase feedback operates, toward the equator [11]. Consistent with this hypothesis, Tan et al. [55] optimized a model for supercooled liquid against observations and found that this substantially increased the model's climate sensitivity (attributing this to the above phase feedback mechanism), but this result should be viewed with caution due to significant changes in the modified model's mean climate, and absence of an impact on overall radiative fluxes in another model where the modified mean climate was more realistic [32]. Thus, while it is plausible that current models have a too-strong negative phase feedback, further work is needed to robustly diagnose and quantify the problem.

\section{Aerosol-Mediated Cloud Feedback}

Finally, there are potential modifications to clouds by aerosols. Since cloud drop number concentrations are sensitive to the aerosol population that acts as cloud condensation nuclei [62], aerosols can alter cloud drop number concentrations and alter cloud optical thickness and CRE (Eq. 1). While the effect most often considered is the forcing due to an exogenous (e.g. anthropogenic) aerosol source, if aerosol amounts change due to climate and this affects clouds, the result would be an aerosol-mediated cloud feedback.

Warmer climates may have different aerosol distributions, either from changes in anthropogenic emissions or by responses of natural aerosols to changes in climate state. Likely mechanisms for the latter could include the impact of ocean wind speed changes on sea salt aerosol or the impact of aridity changes in fire- or dust-producing land regions. Korhonen et al. [34] estimated a substantial negative feedback due to strengthening winds over the Southern Ocean driving aerosol and albedo increases. Note that there is an observed increase in Southern Ocean winds (e.g. [49]), though the observed wind changes may be due to ozone depletion. Gettelman et al. [24] found a similar increase in future wind speed and negative aerosol-mediated cloud feedbacks also arising from changes in dust emission and deposition. In addition, Gettelman et al. [24] found different cloud feedback with different levels of anthropogenic aerosols held constant in time, with a global effect up to $50 \%$ of the total cloud feedback.

Because models treat aerosols and aerosol effects on clouds quite differently, any aerosol-mediated feedback is likely to be very different from one model to another. For example, differences in the base-state aerosol loading across models may alter base state of cloud optical depth (Eq. 1) by altering drop number, and this could cause inter-model spread in cloud feedback. Or different levels of aerosols would create different aerosol feedbacks, aliased into cloud feedback. Thus, aerosol effects could be a contributor to the spread of cloud feedback simulated in newer-generation models; consistently accounting for aerosol effects may reduce the spread of simulated cloud feedback.

\section{Observations of Cloud Feedback and Emergent Constraints}

To what extent can we observe harbingers of these different cloud processes and responses in the present-day climate, and how can these observations improve our understanding of cloud feedback?

One approach is to fit natural co-variability of the topof-atmosphere radiative balance and global surface temperature to the basic linear feedback model of the climate system (see [46]) to infer the feedback parameter (e.g. [21]. This assumes that global-mean cloud radiative effect will respond consistently to a global-mean temperature change regardless of the regional pattern or cause of the change, a strong assumption that must be tested carefully in models (see [6, 47]). Andrews et al. [1] have shown non-linearities in the feedback parameter on short timescales $(<20$ years). Zhou et al. [72] have recently shown that the approach can work with a sufficiently long record, but the available observing record is too short to constrain cloud feedback to a range any narrower than that in current models. It remains to be seen whether more sophisticated approaches might reveal more powerful constraints with the current length of the observational record.

A more indirect paradigm is that of "emergent constraints" (see the review of Klein and Hall [33]), where links are sought between observable characteristics of the present state and feedbacks. Such constraints have typically been discovered by applying a correlation approach to an ensemble of climate models, correlating simulated cloud feedback or sensitivity to some observable quantity; this can be thought of as a highly targeted model evaluation.

Emergent constraints include low cloud dependence on SST and inversion strength in trades or subsidence regimes, which imply positive feedback from these clouds ("Marine Stratocumulus"). Zhai et al. [69] furthermore show that the seasonal cycle of cloud fraction in subsidence regions decreases with increasing SST in a similar way to climate change responses to rising SST. In principle, the emergentconstraint approach could be applied to other feedbacks (cloud height, poleward shift, etc.). So far, the focus has 
been on low clouds because the spread of GCM behavior for subtropical low cloud is broad.

Emergent constraints have also been sought for the total global climate sensitivity. Sherwood et al. [48] found a global constraint based on indices of upward water vapor transport linked to known feedback mechanisms, was previously noted; others have reached similar conclusions of high real-world sensitivity using a range of other observables. However, as pointed out by Klein and Hall [33], none of these other constraints come with an explanatory mechanism and could be fortuitous. Furthermore, the constraints often depend on the processes and feedbacks in particular sub-sets of models [29].

Moreover, microphysical mechanisms might exist that significantly (or systematically) affect cloud feedback even though they may not have been strongly expressed in previous CMIP model ensembles. This may happen through microphysical effects on precipitation in convective clouds [71] or responses to aerosol loading that alter cloud LWP and $N_{c}$ [24].

Thus, emergent constraints must be viewed with suspicion as long as the possibility rem ains that climate models may all be missing some important feedback mechanism (no matter how many constraints appear and even if they are all consistent).

\section{Discussion}

It is clear that cloud feedback is complex, arising from a series of different processes each potentially acting in multiple cloud regimes. Processes relate to the large scale environment (e.g. mixing, moisture flux, radiative cooling) and to cloud microphysics (precipitation efficiency, cloud phase, aerosols). These different regimes and processes are illustrated in Fig. 4 overlying a map of kernel adjusted cloud feedback following Gettelman et al. [24], similar to the multi-model ensemble of Fig. 1c. These regimes may evolve differently in response to climate change, which may confound the search for a single dominant emergent constraint on cloud feedback. Also note that even similar regimes behave differently: the different stratus regions can have different net cloud feebacks (Fig. 1c and Fig. 4).

A subtlety of the problem of cloud feedback is that changes to cloud radiative properties will result from intermediate effects not directly traceable to local surface temperature alone. For example, low cloud changes will respond to the local boundary layer turbulence and stability (Fig. 3). These phenomena are influenced by the strength of the inversion and free tropospheric humidity, in turn governed by large-scale circulations; the motion of the storm tracks is also governed by planetary circulations and temperature gradients. Cloud microphysical responses such as precipitation efficiency might depend on aerosols, also not traceable to local or global temperature.

Our analysis and review highlights the key regimes shown in Fig. 4. (1) Tropical high cloud feedback (Blue in Fig. 4) is likely positive, and depends on the large-scale environment and radiative balance. However, the moisture supply to the upper troposphere may depend on the precipitation efficiency and/or organization of deep convective clouds. (2) Sub-tropical shallow cloud feedback in subsidence regimes (Red in Fig. 4) is also likely positive, and depends on a balance of local and non-local processes. (3) The shallow convective regime (also Red in Fig. 4) also seems highly sensitive to the representation of entrainment between shallow cumulus and their environment. This regime extends to the equatorward branch of the storm

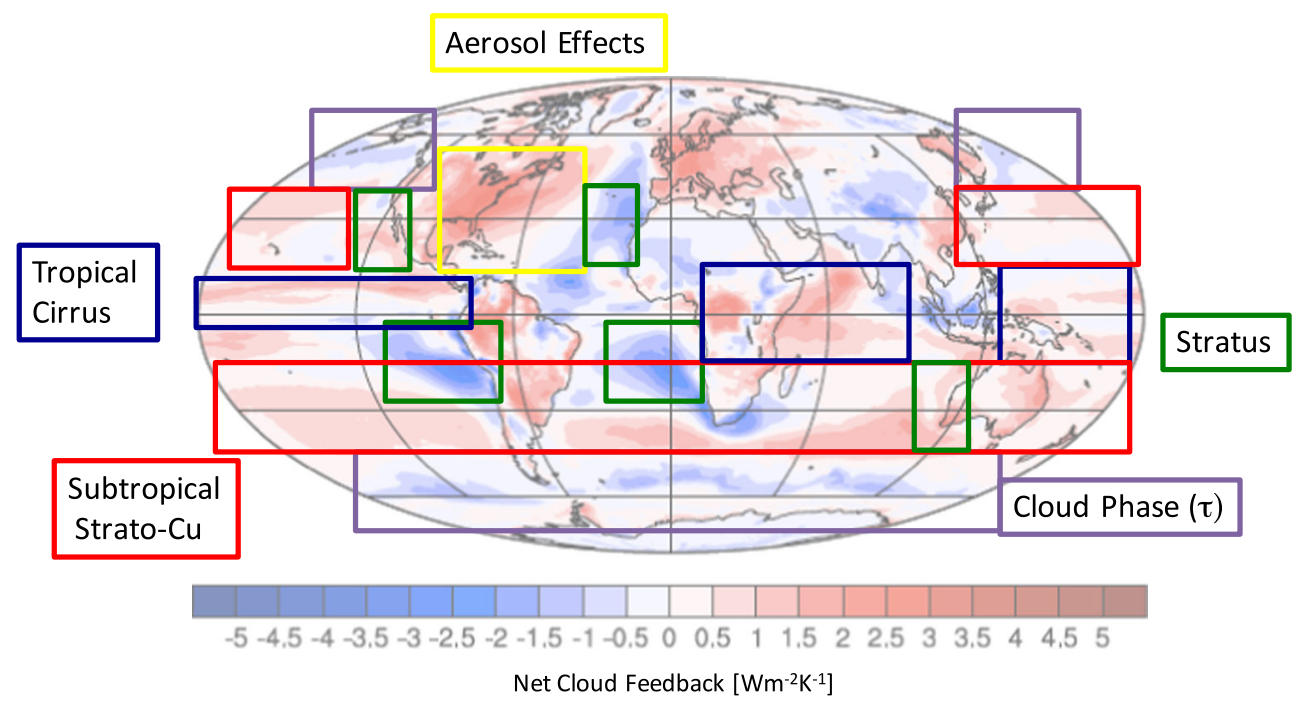

Fig. 4 Cloud Feedback by regime/process. Net kernel adjusted cloud feedback estimate based on simulations in [24] using 20 years each of 30 ensemble members for the end of the 21 st century with RCP8.5 in a single model. Key processes and regimes highlighted with different colors 
tracks, and is also present in mid-latitude cyclones. The subtropics are the largest area of any of the regimes examined, and seem to induce the largest effect.

Tropical and mid-latitude storm systems contain a spectrum of cloud regimes. Warmer frontal clouds in midlatitude cyclones may respond to changes in storm dynamics, but little analysis of cloud feedback in this regime exists. (4) The cold sector of cyclones has cold stratocumulus clouds with super-cooled liquid. In this regime (Purple in Fig. 4) and at higher latitudes (in polar stratiform clouds) the transition from liquid to ice is important for understanding cloud lifetime, and is controlled by mixing/entrainment and microphysics. (5) Cloud phase effects due to thermodynamics are a negative feedback at high latitudes (Purple in Fig. 4) and may also depend on ice nucleation and freezing processes. It remains to sort out any feedback effects of cloud shifts (or not) due to shifts in the storm tracks independent of thermodynamics. (6) Aerosols (Yellow in Fig. 4) may also impact cloud feedbacks, both by providing an aerosol feedback, and by being included in analysis of cloud feedback.

Consensus emerged in Boucher et al. [6] on largescale mechanisms for cloud feedback, particularly for high clouds. Significant progress has been made since then in understanding and observationally constraining the more local responses of shallow clouds and relating shallow cloud feedback to specific processes such as mixing. Deeper circulations (which impact sub-tropical mixing) are also sensitive to the representation of convection in models. Mixing and turbulence are related to several different parameterizations in models, as well as coupled to the general circulation. Refining boundary layer, mixing (diffusion), convection and turbulence schemes through the use of observations and traceability to fine scale models may help to understand and improve our ability to simulate cloud feedbacks.

Current work is also highlighting important ways in which the microphysics and microphysical state of precipitating cloud regimes is important for cloud feedback. These include aerosol-mediated effects and effects on mixed phase clouds, especially in middle and high latitudes. The role of cloud microphysics in setting and altering deep convective precipitation efficiency may also be important for cloud feedback. Significant uncertainties remain in microphysical mechanisms, the treatment of which in climate models is still in its infancy.

Narrowing the spread of simulated cloud feedbacks involves focusing on key regimes and trying to simulate cloud processes with as much fidelity as possible. Aerosol effects in models should be examined for their impact on cloud feedbacks, and the effects from climate changes considered separately as an aerosol feedback. Focusing on regimes leads naturally to a physical basis of key processes for understanding emergent constraints on clouds in the present day. These regimes are complex, and improving the understanding and representation of cloud processes will involve use of observations from targeted field programs in different regimes for detailed comparisons to models at fine to larger scales. Making larger-scale models with more crude formulations traceable to small scale models will help provide a link for those processes that are "mediated" by global and local temperature, but do not respond directly to local temperature changes.

Future studies will also need to account for the diversity of cloud microphysical and aerosol processes in models. Narrowing the spread of cloud feedback may require better accounting for the diversity of processes that contribute to cloud feedback, such as different treatments of the mixed phase regime, models with different complexities of microphysics in convective cloud and different levels of complexity of aerosol processes.

Acknowledgments The National Center for Atmospheric Research is funded by the US National Science Foundation. SCS was funded by Australian Research Council DP140101104.

\section{Compliance with Ethical Standards}

Conflict of Interests On behalf of all authors, the corresponding author states that there is no conflict of interest.

\section{References}

1. Andrews T, Gregory JM, Webb MJ. The dependence of radiative forcing and feedback on evolving patterns of surface temperature change in climate models. J Climate. 2015;28(4):1. doi:10.1175/JCLI-D-14-00545.

2. Bender FAM, Ramanathan V, Tselioudis G. Changes in extratropical storm track cloudiness 1983-2008: Observational support for a poleward shift. Clim Dyn. 2012;38:2037-2053. doi:10.1007/s00382-011-1065-6.

3. Bodas-Salcedo A, Williams K, Field P, Lock A. The surface downwelling solar radiation surplus over the Southern Ocean in the Met Office model: The role of midlatitude cyclone clouds. J Climate. 2012;25(21):7467-7486.

4. Bony S, Colman R, Kattsov VM, Allan RP, Bretherton CS, Dufresne JL, Hall A, Hallegatte S, Holland MM, Ingram W, Randall DA, Soden BJ, Tselioudis G, Webb MJ. How well do We understand and evaluate climate change feedback processes? J Climate. 2006;19(15):1. doi:10.1175/JCLI3819.

5. Bony S, Stevens B, Coppin D, Becker T, Reed KA, Voigt A, Medeiros B. Thermodynamic control of anvil cloud amount. PNAS. 2016;113(32):8927-8932. doi:10.1073/pnas.1601472113.

6. Boucher O, Randall D, Artaxo P, Bretherton C, Feingold G, Forster P, Kerminen VM, Kondo Y, Liao H, Lohmann U, Rasch P, Satheesh SK, Sherwood S, Stevens B, Zhang XY. Clouds and aerosols. Climate change 2013: The Physical Science Basis. Contribution of Working Group I to the Fifth Assessment Report of the Intergovernmental Panel on Climate Change, Cambridge Universtiy Press. In: Stocker TF, Qin D, Plattner GK, Tignor M, Allen SK, Boschung J, Nauels A, Xia Y, Bex V, and Midgley PM, editors; 2013. 
7. Bretherton CS. Insights into low-latitude cloud feedbacks from high-resolution models. Phil Trans R Soc A. 2015;373(2054):20140,415. doi:10.1098/rsta.2014.0415.

8. Bretherton CS, Blossey PN. Low cloud reduction in a greenhousewarmed climate: Results from Lagrangian LES of a subtropical marine cloudiness transition. J Adv Model Earth Syst. 2014;6(1):91-114. doi:10.1002/2013MS000250.

9. Brient F, Bony S. How may low-cloud radiative properties simulated in the current climate influence low-cloud feedbacks under global warming?. Geophys Res Lett. 2012;39(20):L20,807. doi:10.1029/2012GL053265.

10. Brient F, Bony S. Interpretation of the positive low-cloud feedback predicted by a climate model under global warming. Clim Dyn. 2013;40(9-10):2415-2431. doi:10.1007/s00382-011-1279-7.

11. Ceppi P, Hartmann DL, Webb MJ. Mechanisms of the Negative Shortwave Cloud Feedback in Middle to High Latitudes. J Climate. 2016a;29(1):139-157. doi:10.1175/JCLI-D-15-0327.1.

12. Ceppi P, McCoy DT, Hartmann DL. Observational evidence for a negative shortwave cloud feedback in middle to high latitudes. Geophys Res Lett. 2016b;43(2015GL067499). doi:10.1002/2015GL067499.

13. Cess RD, et al. CLoud feedback in atmospheric general circulation models: An update. J Geophys Res. 1996;101(D8):12,791-12, 794.

14. Chen G, Held IM. Phase speed spectra and the recent poleward shift of Southern Hemisphere surface westerlies. Geophys Res Lett. 2007;34(L21805). doi:10.1029/2007GL031200.

15. Choi YS, Ho CH, Park CE, Storelvmo T, Tan I. Influence of cloud phase composition on climate feedbacks. J Geophys Res.Atmos. 2014;119(7):3687-3700. doi:10.1002/2013JD020582.

16. Colman R. A comparison of climate feedbacks in general circulation models. Clim Dyn. 2003;20:865-873.

17. Davis SM, Rosenlof KH. A Multidiagnostic interomparison of tropical-width time series using reanalyses and satellite observations. joc. 2012;25:1061-1078. doi:10.1175/JCLI-D-11-00127.1.

18. Dessler AE. A determination of the cloud feedback from climate variations over the past decade. Science. 2010;330:1523-1527. doi:10.1126/science.1192546.

19. Fasullo JT, Sanderson BM, Trenberth KE. Recent progress in constraining climate sensitivity with model ensembles. Curr Clim Chang Rep. 2015;1(4):268-275.

20. Flato G, Marotzke J, Abiodun B, Braconnot P, Chou SC, Collins W, Cox P, Driouech F, Emori S, Eyring V, Forest C, Gleckler P, Guilyardi E, Jakob C, Kattsov V, Reason C, Rummukainen M. Evaluation of climate models. Climate change 2013: The Physical Science Basis. Contribution of Working Group I to the Fifth Assessment Report of the Intergovernmental Panel on Climate Change, Cambridge Universtiy Press. In: Stocker TF, Qin D, Plattner GK, Tignor M, Allen SK, Boschung J, Nauels A, Xia Y, Bex V, and Midgley PM, editors; 2013.

21. Forster PMF, Gregory JM. The climate sensitivity and its components diagnosed from Earth radiation budget data. J Clim. 2006;19(1):39-52.

22. Gettelman A, Chen CC. The Climate Impact of Aviation Aerosols. grl. 2013;40(L50520). doi:10.1029/grl.50.520.

23. Gettelman A, Kay JE, Shell KM. The evolution of climate feedbacks in the community atmosphere model. J Clim. 2012;25(5):1453-1469. doi:10.1175/JCLI-D-11-00197.1.

24. Gettelman A, Lin L, Medeiros B, Olson J. Climate feedback variance and the interaction of aerosol forcing and feedbacks. J Clim. 2016;29(18):6659-6675. doi:10.1175/JCLI-D-16-0151.1.

25. Gordon ND, Klein SA. Low-cloud optical depth feedback in climate models: Optical Depth Feedback. J Geophys Res.-Atmos. 2014;119(10):6052-6065. doi:10.1002/2013JD021052.
26. Grise KM, Polvani LM. Is climate sensitivity related to dynamical sensitivity?. J Geophys Res Atmos. 2016;121(2015JD024687). doi:10.1002/2015JD024687.

27. Grise KM, Polvani LM, Tselioudis G, Wu Y, Zelinka MD. The ozone hole indirect effect: Cloud-radiative anomalies accompanying the poleward shift of the eddy-driven jet in the Southern Hemisphere. Geophys Res Lett. 2013;40(14):3688-3692. doi:10.1002/grl.50675.

28. Hartmann DL, Larson K. An important constraint on tropical cloud - climate feedback. Geophys Res Lett. 2002;29(20):1951. doi:10.1029/2002GL015835.

29. Kamae Y, Ogura T, Watanabe M, Xie SP, Ueda H. Robust cloud feedback over tropical land in a warming climate. J Geophys Res Atmos p 2015JD024525. 2016a. doi:10.1002/2015JD024525.

30. Kamae Y, Shiogama H, Watanabe M, Ogura T, Yokohata $\mathrm{T}$, Kimoto M. Lower tropospheric mixing as a constraint on cloud feedback in a Multi-Parameter Multi-Physics Ensemble. J Climate. 2016b. doi:10.1175/JCLI-D-16-0042.1.

31. Kay JE, Deser C, Phillips A, Mai A, Hannay C, Strand G, Arblaster JM, Bates SC, Danabasoglu G, Edwards J, Holland M, Kushner P, Lamarque JF, Lawrence D, Lindsay K, Middleton A, Munoz E, Neale R, Oleson K, Polvani L, Vertenstein M. The community earth system model (CESM) large ensemble project: a community resource for studying climate change in the presence of internal climate variability. Bull Amer Meteor Soc. 2014 doi:10.1175/BAMS-D-13-00255.1.

32. Kay JE, Wall C, Yettella V, Medeiros B, Hannay C, Caldwell P, Bitz C. Global climate impacts of fixing the southern ocean shortwave radiation bias in the community earth system model (CESM). J Clim. 2016;29(12):4617-4636. doi:10.1175/JCLI-D-15-0358.1.

33. Klein SA, Hall A. Emergent Constraints for Cloud Feedbacks. Curr Clim Change Rep. 2015;1(4):276-287. doi:10.1007/s40641-015-0027-1.

34. Korhonen H, Carslaw KS, Forster PM, Mikkonen S, Gordon ND, Kokkola H. Aerosol climate feedback due to decadal increases in Southern Hemisphere wind speeds. Geophys Res Lett. 2010;37(2):L02,805. doi:10.1029/2009GL041320.

35. Mauritsen T, Stevens B. Missing iris effect as a possible cause of muted hydrological change and high climate sensitivity in models. Nature Geosci. 2015;8(5):346-351. doi:10.1038/ngeo2414.

36. McCoy DT, Tan I, Hartmann DL, Zelinka MD, Storelvmo T. On the relationships among cloud cover, mixed-phase partitioning, and planetary albedo in GCMs. J Adv Model Earth Syst pp n/an/a. 2016. doi:10.1002/2015MS000589.

37. Murphy DM, Koop T. Review of the vapour pressure of ice and supercooled water for atmospheric applications. Q J R Meteorol Soc. 2005;131(608):1539-1565.

38. Myers TA, Norris JR. Reducing the uncertainty in subtropical cloud feedback. Geophys Res Lett p 2015GL067416. 2016. doi:10.1002/2015GL067416.

39. Nishant N, Sherwood SC, Geoffroy O. Radiative driving of shallow return flows from the ITCZ. J Adv Model Earth Syst. 2016;8(2):831-842. doi:10.1002/2015MS000606.

40. Norris JR, Allen RJ, Evan AT, Zelinka MD, O’Dell CW, Klein SA. Evidence for climate change in the satellite cloud record. Nature. 2016;536(7614):72-75. doi:10.1038/nature18273.

41. Qu X, Hall A, Klein SA, Caldwell PM. On the spread of changes in marine low cloud cover in climate model simulations of the 21st century. Clim Dyn. 2014;42(9-10):2603-2626. doi:10.1007/s00382-013-1945-z.

42. Qu X, Hall A, Klein SA, Caldwell PM. The strength of the tropical inversion and its response to climate change in 18 CMIP5 models. Clim Dyn. 2015a;45(1-2):375-396. doi:10.1007/s00382-014-2441-9. 
43. Qu X, Hall A, Klein SA, DeAngelis AM. Positive tropical marine low-cloud cover feedback inferred from cloud-controlling factors. Geophys Res Lett. 2015b;42(18):2015GL065,627. doi:10.1002/2015GL065627.

44. Rieck M, Nuijens L, Stevens B. Marine boundary layer cloud feedbacks in a constant relative humidity atmosphere. J Atmos Sci. 2012;69(8):2538-2550. doi:10.1175/JAS-D-11-0203.1.

45. Seifert A, Heus T, Pincus R, Stevens B. Large-eddy simulation of the transient and near-equilibrium behavior of precipitating shallow convection. J Adv Model Earth Syst pp n/a-n/a. 2015. doi:10.1002/2015MS000489.

46. Sherwood SC, Nishant N. Atmospheric changes through 2012 as shown by iteratively homogenized radiosonde temperature and wind data (IUKv2). Environ Res Lett. 2015;10(5):054,007. doi:10.1088/1748-9326/10/5/054007.

47. Sherwood SC, Roca R, Weckwerth TM, Andronova NG. Tropospheric water vapor, convection, and climate. Rev Geophys. 2010;48(2). doi:10.1029/2009RG000301.

48. Sherwood SC, Bony S, Dufresne JL. Spread in model climate sensitivity traced to atmospheric convective mixing. Nature. 2014;505(7481):37-42. doi:10.1038/nature12829.

49. Sherwood SC, Bony S, Boucher O, Bretherton C, Forster PM, Gregory JM, Stevens B. Adjustments in the Forcing-Feedback framework for understanding climate change. Bull Amer Meteor Soc. 2015;96(2):217-228. doi:10.1175/BAMS-D-13-00167.1.

50. Soden BJ, Vecchi GA. The Vertical Distribution of Cloud Feedback in Coupled Ocean-Atmosphere Models. Geophys Res Lett. 2011;38(12). doi:10.1029/2011GL047632.

51. Soden BJ, Held IM, Colman R, Shell KM, Kiehl JT, Shields CA. Quantifying climate feedbacks using radiative kernels. J Clim. 2008;21(14):3504-3520. doi:10.1175/2007JCLI2110.1.

52. Somerville RCJ, Remer LA. Cloud optical thickness feedbacks in the CO2 climate problem. J Geophys Res. 1984;89(D6):96689672. doi:10.1029/JD089iD06p09668.

53. Stephens GL. Radiation profiles in extended water clouds. II: Parameterization schemes. J Atmos Sci. 1978;35(11):2123-2132.

54. Stephens GL, Li J, Wild M, Clayson CA, Loeb N, Kato S, L'Ecuyer T, Jr PWS, Lebsock M, Andrews T. An update on Earth's energy balance in light of the latest global observations. Nature Geosci. 2012;5(10):691-696. doi:10.1038/ngeo1580.

55. Tan I, Storelvmo T, Zelinka MD. Observational constraints on mixed-phase clouds imply higher climate sensitivity. Science. 2016;352(6282):224-227. doi:10.1126/science.aad5300.

56. Terai CR, Klein SA, Zelinka MD. Constraining the low-cloud optical depth feedback at middle and high latitudes using satellite observations. J Geophys Res Atmos p 2016JD025233. 2016. doi:10.1002/2016JD025233.

57. Tomassini L, Voigt A, Stevens B. On the connection between tropical circulation, convective mixing, and climate sensitivity. QJR Meteorol Soc. 2015;141(689):1404-1416. doi:10.1002/qj.2450.

58. Tselioudis G, Rossow WB, Rind D. Global patterns of cloud optical thickness variation with temperature. J Clim. 1992;5(12):1484-1495.

59. Tselioudis G, Lipat BR, Konsta D, Grise KM, Polvani LM. Midlatitude cloud shifts, their primary link to the Hadley cell, and their diverse radiative effects. Geophys Res Lett p 2016GL068242. 2016. doi:10.1002/2016GL068242.

60. Tsushima Y, Emori S, Ogura T, Kimoto M, Webb MJ, Williams KD, Ringer MA, Soden BJ, Li B, Andronova N. Importance of the mixed-phase cloud distribution in the control climate for assessing the response of clouds to carbon dioxide increase: A multi-model study. Clim Dyn. 2006;27:113-126. doi:10.1007/s00382-006-0127-7.

61. Tsushima Y, Ringer MA, Webb MJ, Williams KD. Quantitative evaluation of the seasonal variations in climate model cloud regimes. Clim Dyn. 2012;41(9-10):2679-2696. doi:10.1007/s00382-012-1609-4.

62. Twomey S. The influence of pollution on the shortwave albedo of clouds. J Atmos Sci. 1977;34(7):1149-1152.

63. Vial J, Dufresne JL, Bony S. On the interpretation of intermodel spread in CMIP5 climate sensitivity estimates. Clim Dyn. 2013;41(11-12):3339-3362. doi:10.1007/s00382-013-1725-9.

64. Webb MJ, Lock AP, Bretherton CS, Bony S, Cole JNS, Idelkadi A, Kang SM, Koshiro T, Kawai H, Ogura T, Roehrig R, Shin Y, Mauritsen T, Sherwood SC, Vial J, Watanabe M, Woelfle MD, Zhao M. The impact of parametrized convection on cloud feedback. Phil Trans R Soc A. 2015;373(2054):20140,414. doi:10.1098/rsta.2014.0414.

65. Yue Q, Kahn BH, Fetzer EJ, Schreier M, Wong S, Chen $X$, Huang X. Observation-based Longwave cloud radiative kernels derived from the A-Train. J Clim. 2016;29(6):2023-2040. doi:10.1175/JCLI-D-15-0257.1.

66. Zelinka M, Klein S, Hartmann D. Computing and partitioning cloud feedbacks using cloud property histograms. Part II: Attribution to Changes in Cloud Amount, Altitude, and Optical Depth. J Clim. 2012;25(11):3736-3754.

67. Zelinka MD, Hartmann DL. Why is longwave cloud feedback positive?. J Geophys Res. 2010;115(D16). doi:10.1029/2010JD013817.

68. Zelinka MD, Zhou C, Klein SA. Insights from a refined decomposition of cloud feedbacks. Geophys Res Lett p 2016GL069917. 2016. doi:10.1002/2016GL069917.

69. Zhai C, Jiang JH, Su H. Long-term cloud change imprinted in seasonal cloud variation: More evidence of high climate sensitivity. Geophys Res Lett 42(2015GL065911). 2015. doi:10.1002/2015GL065911.

70. Zhang M, Lin W, Klein S, Bacmeister J, Bony S, Cederwall R, Del Genio A, Hack J, Loeb N, Lohmann U, et al. Comparing clouds and their seasonal variations in 10 atmospheric general circulation models with satellite measurements. J Geophys Res. 2005;110(D15):D15.

71. Zhao M, Golaz JC, Held IM, Ramaswamy V, Lin SJ, Ming Y, Ginoux P, Wyman B, Donner LJ, Paynter D, Guo H. Uncertainty in model climate sensitivity traced to representations of cumulus precipitation microphysics. J Clim. 2016;29(2):543-560. doi:10.1175/JCLI-D-15-0191.1.

72. Zhou L, Zhang M, Bao Q, Liu Y. On the incident solar radiation in CMIP5 models: Incident Solar Radiation in CMIP5 Models. Geophys Res Lett. 2015;42(6):1930-1935. doi:10.1002/2015GL063239. 